\title{
Application prospects of distance learning technologies in the system of additional vocational education
}

\author{
Svetlana Demina ${ }^{1, *}$ and Valery Postyrnak ${ }^{2}$ \\ ${ }^{1}$ Moscow Technological Institute, 119334, Moscow, Russia \\ ${ }^{2}$ Moscow Institute of Banking, 105203, Moscow, Russia
}

\begin{abstract}
In modern times the educational institutions of additional vocational education have to take into account mainly conflicting factors. On the one hand, these are the demands of employers to the quality of the educational process, on the other - the need to cut costs on employee training. This article states the basic features of use of distance technologies that allow to optimize training costs and to solve the problem of development of practical skills of listeners. The demand structure for programs of additional vocational education is presented on the example of several business schools. Besides the application topicality of remote educational technologies to support the learning process on-the-job is substantiated.
\end{abstract}

\section{Introduction}

In modernization process of Russia's economy the value of distance learning technologies in the system of additional vocational education is increasing significantly. The analysis of modern and perspective educational forms shows that the use of remote technologies for the realization of the educational process in the additional vocational education system is high-potential.

Educational institutions of additional vocational education appear today in the conditions when it is necessary to consider the largely conflicting factors. On the one hand, increasing demands of employers to the quality of the educational process: individualization, improvement of educational programs; the introduction of a larger amount of practical training. On the other hand, the urgent task is the reduction of costs for training employees.

For example, according to the Moscow Business School, more than $80 \%$ of employers are interested in the professional development of staff on-the-job. This requirement is due to the fact that off-the-job training burdens the employer with substantial costs associated with the need to pay travel expenses and outages of the company.

During off-the-job training the employee is unable to perform his/her functions. During the training period the employee needs to be replaced by another person. Thus, it is not always possible without expense for the company as well as for the employee. Senior and middle managers often indicate that after their return from the duty journey they are forced into an emergency mode to carry on the work that has accumulated over the period of their absence from the workplace. It is obvious that the functions of individual employees may not be delegated in full to another person. As a rule, these functions can be performed only by people with special knowledge and access to specific information. Therefore, such employees cannot be permanently withdrawn from work.

\section{Research and discussion}

The interest in training on-the-job is shown not only by the employers but also by the workers themselves. This conclusion is supported by data from the students of the Academy of business and innovative technologies survey. Conducted by the authors in 2016, the survey showed that $55 \%$ of the Academy applicants are interested in learning remotely on-the-job. $32 \%$ of the respondents would prefer learning with partial on-thejob, $13 \%$ - do not want to combine learning and work.

The workers do not wish to combine training and labor because they are afraid to be found in a situation, when the total duration of their working time and training will greatly exceed the daily standard working time [1].

The desire to learn with partial on-the-job was showed basically by those employees, who would like to have new useful and interesting contacts for experience exchange and establishing partnership during the face-toface classes.

The study showed that in general working people are showing more interest in learning if they see the need for training and the possibility of applying its results to improve their professional activities. For many adult learners the distance learning technology is associated with the ability to work under individual schedule.

* Corresponding author: $\underline{\mathrm{s} \text { demina } @ \text { mti.edu.ru }}$ 
Among the main advantages of using distance technologies in the system of additional vocational education are the following:

1) the possibility of obtaining access to training courses and the opportunity to choose the time for training. When applying for refresher courses and professional courses, students often note, that they are concerned about the fact that for some reasons they won't be able to cope with the curriculum (there is no possibility to interrupt the work, geographical distance, illness, etc.);

2) the reduction of training costs: for an employee there is no need to travel further afield and for organizations to send employees on business trips;

3) wide possibilities for the organization of andragogical models of learning organization. Any form of learning, in which the teacher and students are separated in time and space can be considered as distance learning [2]. However, the e-learning becomes effective only when the learner is ready to take responsibility for defining the field of study, the choice of methods, the training periods and the evaluation criteria. Experts note, that the additional vocational education students, as adults, are more responsible for their learning process. Adult learners often bring to the program their own experiences and their life values, try to relate the learning situation to their professional goals and objectives.

At the same time, many students experience difficulties in learning due to psychological reasons: fear of looking incompetent, the discrepancy of self-image of «successful person» to the role of a student. Indirect interaction between the teacher and the students in distance learning system partially solves this problem. The authors ' survey has showed that students at the age from 30 to 45 years are more likely to pay attention to the fact that the system of self-regulation in distance learning programs leaves more opportunities for selfcriticism and self-evaluation, compared to full-time courses. Thus, the expansion of distant educational technologies in the system of additional vocational education stands out as a promising direction. This direction requires a systematic approach and developing of mechanisms for its implementation.

The quality of specialists' training through the distance learning technologies is provided by the capabilities of modern computing equipment and appropriate organization of the educational process. It should be noted that unlike the traditional educational system, in the system of additional vocational education the main attention is paid not only to the process of learning, but also to development opportunities of the listener for more practical skills.

In the system of distance learning the task of learning is provided by the presence of electronic versions of relevant materials. In addition, in the timetable it is advisable to plan and conduct webinars (online seminars), which are read by highly qualified specialists. Seminars conducted online enable the trainees to communicate with the teacher. This makes the online seminar similar to traditional.
A convenient webinar format allows you to solve the problem of employment of students and lecturers. The experience of the organization of webinars in Moscow Business School shows that experienced trainers, experts, consultants and top managers agree more willingly to conduct webinars from your office, because of their employment. For the listeners the online workshops is the opportunity for remote participation, the opportunity to listen to a seminar offline at any time (after placing the workshop in the distance learning system).

If necessary, you can conduct video consultations. This will help to improve the quality of consolidate training material and to organize the educational process so that the student could control the degree of objectives achievement.

In addition, in the system of distance learning there are appropriate references, allowing to obtain the necessary information related to the training.

The task of developing practical skills is solved by using special software for professional activity simulation, as well as programs that implement the procedure for solving the professionally oriented problems.

Thus, the starting point of additional vocational education is the acquisition of specific experience. According to the authors, training in the additional vocational education system should include the following stages:

- awareness of their incompetence;

- awareness of the need for skills development to a new level;

- obtaining direct experience;

- the comprehension of the experience;

- experimental verification of new knowledge;

- independent application of acquired knowledge in practice.

\section{Conclusions}

The learning process can begin from any stage. It occurs cyclically until the desired skill is formed. The use of distance learning technologies in the training in the additional vocational education system should include the following stages system allows not to interrupt this process. In the system of distance learning the improvement of professional skills may be organized in the form of an endless spiral of competence development: after the training, the listener is not removed from the system, he receives the information about actual changes in legislation, new professional requirements, methods of professional growth.

\section{References}

1. Labor code of the Russian Federation (Federal Law №. 197-FZ of 2001).

1. The law «On education in the Russian Federation» (Federal Law №. 273-FZ of 2012) 